\title{
Macedo e o romance romântico
}

Karin Volobuef UNESP-Araraquara

Resumo: Joaquim Manuel de Macedo foi um escritor que gozou de enorme sucesso junto ao público do séc. XIX; já a posteridade tratou sua obra com muitas reservas. A despeito dessa severidade dos críticos, é inegável que a contribuição de Macedo não se restringe às suas obras em si, mas estende-se à própria concepção de romance durante o Romantismo brasileiro. Essa concepção é carregada de observação do dia-a-dia e de uma estética amparada em elementos do Romantismo europeu. Em A luneta mágica, ao contrário, Macedo explora os veios fantástico e maravilhoso, mostrando ousadia critica e criativa, motivo pelo qual o romance contrasta vivamente com as outras produçôes românticas no Brasil.

Palavras-chave: Joaquim Manuel de Macedo; A luneta mágica; A Moreninha.

Joaquim Manuel de Macedo (1820-1882) foi um dos autores de maior sucesso junto ao público de sua época. Sua obra é vasta: começando com A Moreninha, de 1844 (mesmo ano de sua formatura na faculdade), Macedo publicou avantajado número de romances, novelas, contos, passando ainda pelo teatro e poesia, e escrevendo inclusive obras biográficas e até pedagógicas, como é o caso de Mulheres célebres (1878), texto destinado ao ensino primário feminino.

1. Uma breve relação de suas obras compreende os contos reunidos em ... 
Essa forte presença no espaço editorial fez-se acompanhar de uma constante prática de propaganda: Marlyse Meyer, em seu extenso estudo sobre o folhetim, ${ }^{2}$ menciona que A Moreninha, mas também outras obras do autor, capitanearam durante anos as listas de livros promovidas nos jornais. Assim, ainda que nenhum dos romances posteriores tenha tido tão calorosa acolhida como o primeiro, a boa vendagem de livros andou de mãos dadas com a preocupação de Macedo em adequar sua ficção ao horizonte dos leitores. Para Antonio Candido, ${ }^{3}$ estamos diante do autor brasileiro do séc. XIX que teve maior afinidade com seu público, já que sempre teria se esforçado por tornar seus textos de fácil e rápida assimilação por seus leitores.

Esse traço, de um modo ou outro, foi sendo sublinhado por gerações de críticos, historiadores da literatura e pesquisadores em geral, que sempre viram em Macedo um autor ingênuo e sem criatividade, cujos voos literários foram rasos e - com exceção de sua obra inaugural -, sem fôlego para perdurar no tempo e conseguir causar impacto sobre as épocas posteriores. ${ }^{4}$ Desde Sílvio Romero, a posteridade se mostrou severa com nosso autor; ${ }^{5}$ na recente História da literatura brasileira, publicada em 2011 por Carlos Nejar, em meio às 1103 páginas do livro, o capítulo "Joaquim Manuel de Macedo e A Moreninha" não chega sequer a ocupar duas páginas inteiras, começando na p. 108 e terminando já na p. 109.

1. ... Os romances da semana (1861); os romances A Moreninha (1844), O moço loiro (1845), Os dois amores (1848), Rosa (1849), Vicentina (1853), O forasteiro (1856), Rio do quarto (1869), A luneta mágica (1869), As mulheres de mantilha (1870-1871), A namoradeira (1870), Um noivo e duas noivas (1871), etc.; a novela As vítimas-algozes (1869); as sátiras políticas A carteira do meu tio (1855) e Memórias do sobrinho do meu tio (1867-1868). Ele ainda escreveu crônicas sobre a cidade do Rio de Janeiro, a exemplo de Memórias da Rua do Ouvidor (1878) e Um passeio pela cidade do Rio de Janeiro (1862-1863), e a biografia Ano biográfico brasileito (1876). Para o teatro compôs O cego (1845), O fantasma branco (1856), O primo da Califórnia (1858), Luxo e vaidade (1860), O novo Otelo (1863), A torre em concurso (1863), Lusbela (1863), Cincinato Quebra-Louças (1873). Na poesia deixou A nebulosa (1857).

2. MEYER. Folhetim, p. 293.

3. CANDIDO. Macedo, realista e romântico, p. 10; CANDIDO. Formação da literatura brasileira, p. 137.

4. Veja-se, p. ex., ALENCAR. José de Alencar e a ficção romântica, p. 246.

5. Cf. SERRA. Joaquim Manuel de Macedo ou Os dois Macedos, p. 229. 
Não obstante essas reservas, o papel de Macedo para a sedimentação de nosso romance foi sublinhado por Massaud Moisés:

[Macedo] enceta a nossa ficção propriamente romântica, e aqui também se tornou mestre, ao menos enquanto durou o modelo cultural vigente após a Independência. Seus romances obedecem a uma esquematização que, duma forma ou doutra, seria empregada pelos ficcionistas contemporâneos e pósteros, desde Alencar até Machado de Assis. Criou, por conseguinte, o nosso padrão de romance romântico, diverso do europeu, notadamente o português, não só pela matéria, extraída de nossa conjuntura sócioeconômica-cultural, mas também pela estrutura e linguagem. Ficcionista nato, legítimo contador de histórias, seus romances descortinam rasgos de nossa psique mais profunda e revelam um processo muito nosso de organizar a matéria narrativa.

O "padrão de romance romântico" instaurado por Macedo em 1844 delineia-se em um período no qual a prosa ainda estava lançando âncora em nosso país. Umas tantas obras sem dúvida antecederam Macedo, e isso até com precedência de mais de século: entre elas, A História do predestinado peregrino e de seu irmão Precito (1682), de Alexandre de Gusmão; o Compêndio narrativo do peregrino da América (1728), de Nuno Marques Pereira; ou, ainda, As aventuras de Diófanes (1758), de Teresa Margarida da Silva e Orta. Para Heron de Alencar, no entanto, "Quando muito, as duas primeiras podem ser consideradas como antecedentes embrionários e isolados do nosso romance, sem qualquer continuidade, sem uma linha de desenvolvimento unitária. Quanto ao livro de Teresa Margarida, [...] não é brasileiro, não diz respeito ao Brasil, nem exerceu a mínima influência em nossa literatura”.

A despeito da precedência dessas obras, diversos traços afastam-nas tanto do âmbito romântico quanto das fronteiras do romance: a conformidade com convenções de base neoclássica; a dimensão didática e/ou edificante dos escritos em prosa da época; e mesmo a condição de colônia do país, pela qual estava não apenas proibida a imprensa brasileira, como ainda era exercido rígido controle da Metrópole sobre importação e comercialização de livros estrangeiros, mantendo enforcada a liberdade de expressão e a circulação de ideias, o que

6. MOISÉs. História da literatura brasileira, p. 79 - nosso grifo.

7. ALENCAR. José de Alencar e a ficção romântica, p. 233. 
afeta drasticamente a possibilidade de pleno desenvolvimento de um gênero como o romance (em essência aberto às mais variadas formas e matérias).

A chegada da Família Real, que trouxe a abertura dos portos e a criação da primeira faculdade, também colocou em movimento as engrenagens que viriam a construir nossa prosa de ficção. Assim, o acesso mais amplo a obras estrangeiras e a traduções (portuguesas ou francesas) significou um impulso fundamental. E, ainda antes de Macedo, foram lançadas várias obras pioneiras: por exemplo, em 1826, a (talvez) primeira novela brasileira - Statira, e Zoroastes -, de Lucas José de Alvarenga; em 1839, Os assassinos misteriosos, ou A paixão dos diamantes, de Justiniano José da Rocha; em 1841, As duas órfãs, de Joaquim Norberto de Souza e Silva; e, em 1843, O filho do pescador-romance brasileiro, de Antônio Gonçalves Teixeira e Sousa.

Sobre esse momento ainda embrionário e suas obras ficcionais vale aqui reproduzir o comentário de Domício Proença Filho:

O que se queria de um texto dito literário, no Brasil dos anos 40 do século passado [XIX]? O que se esperava de uma narrativa ficcional, numa sociedade em formação? De um lado, como acontece atualmente com a literatura de massa, uma boa história que interessasse ao público, carregada de peripécias, mistério, suspense, um texto que prendesse pela trama; de outro, um texto que atendesse às expectativas dos avalizadores, quase todos escritores formados em Coimbra, como Gonçalves Dias [...]. ${ }^{8}$

As obras desses precursores, como Justiniano José da Rocha e Teixeira e Sousa, oscilam entre conto, novela e romance, mostrando-se como composições ainda em busca de perfil narrativo mais definido. Nas palavras de Temístocles Linhares, Macedo, por seu turno, consegue "impor um gênero sem tradição que Teixeira e Sousa não soubera explorar um ano antes, confundindo a sua construção com a do teatro ou a das narrativas poéticas românticas que ainda continuariam a subsistir." Linhares vê a obra de Macedo como centrada no "excesso de individualismo e [n]o amor", mas, a despeito dos arroubos sentimentais, seus personagens

8. PROENÇA FILHO. O filho do pescador: o primeiro romance brasileiro, p. XXIX - grifo no original.

9. LINHARES. História crítica do romance brasileiro (1728-1981), p. 48. 
não cometiam as asneiras trágicas e descabeladas dos heróis de $O$ filho do pescador:

Os homens que aparecem nos romances do autor de $A$ Moreninha não resta dúvida que eram mais sensatos e se atinham a condições de vida mais razoáveis. Não morriam à toa, não matavam a torto e a direito. O sentimentalismo neles não ia ao ponto de esquecer a necessidade de enfrentar mais seriamente a difícil travessia da vida. Se não convertiam a dor em criação ou glória, pelo menos a transformavam em resignação e até em esperança num mundo sempre passível de melhoria. ${ }^{10}$

Da análise de Linhares depreendemos que o chamado Macedinho dos "romances da mesa de chá" e das donzelas casadoiras, a despeito de sua propalada ingenuidade e conformismo, conseguiu ultrapassar em seus textos o estágio alcançado por seus precursores imediatos, e instaurou na novelística nacional enredos mais verossímeis, tramas melhor costuradas e personagens capazes de convencer o leitor e estimular a identificação. Macedo, assim, não foi o primeiro prosador ou romancista, mas pode ser considerado aquele que elevou o gênero a um novo patamar entre nós - permanecendo sua Moreninha no cânone escolar até os nossos dias em vista de seu caráter de marco sinalizador da nascente prosa romântica.

No contexto pós-napoleônico de interesse pela ficção em prosa, Macedo - aliás, formado em Medicina no Rio de Janeiro e não no Exterior - cria uma obra em que focaliza a vida na capital brasileira e em que trata temas e personagens culturalmente afins ao panorama nacional e não ao estrangeiro. Em seu romance de estreia, três mocinhas são apresentadas a Augusto após a chegada na ilha: uma loira, uma pálida e uma morena cor de jambo. ${ }^{12}$ As duas primeiras encarnam ideais europeus - a harmonia clássica e a lividez romântica; a terceira - descrita como "interessante, travêssa e engraçada" da população e do cenário brasileiros, ganhando valor emblemático. E, ao contrário do que Alencar fará em O guarani (1857), a protagonista é a mocinha de tipo nacional.

10. LINHARES. História crítica do romance brasileiro (1728-1981), p. 48.

11. Designação de Antonio Cândido para as obras de Macedo e várias de Alencar, conforme indicação de LINHARES. História crítica do romance brasileiro (17281981), p. 49.

12. MACEDO. A Moreninha, p. 34-35.

13. MACEDO. A Moreninha, p. 35. 


\section{Para Wilson Martins,}

O romance urbano, na e da sociedade brasileira do século XIX, encontra em Macedo o seu verdadeiro criador que, mesmo no nível da qualidade, nada perde em cotejo com José de Alencar (o que digo como elogio para ambos [...]). Macedo, ao contrário do que geralmente se pensa, lançou o romance social [...], mais do que o herói romanesco. A sua leitura nem sempre retribui em prazer estético o que custa em paciência e boa vontade - mas a sua releitura o aponta, sem sombra de dúvida, como dos grandes patriarcas da arte do romance entre nós. Ou, da história do romance brasileiro na sua vontade de se transformar em arte de literatura. ${ }^{14}$

Em conformidade com esse empenho - de conotação nacionalista e artística - o amor entre Augusto e Carolina não vence apenas a barreira dos desencontros e mal-entendidos. Os laços que os unem firmam-se e encontram sua significação mais verdadeira em duas etapas cronologicamente anteriores. O passado dá arrimo e profundidade ao presente.

A primeira etapa - relatada nos capítulos 7 e 8 - corresponde à meninice de Augusto e Carolina, ou sete anos antes do desenrolar de eventos do enredo, quando eles se conheceram e desde então guardam: ele, um breve branco que simboliza a candura da menina; ela, um verde que representa a esperança do menino. ${ }^{15}$ Essa etapa imprime ao romance o peso do destino implacável - colocando-o na mesma senda dos mitos da Antiguidade. Ao invés de uma sibila no oráculo, quem profetiza a união das duas crianças e providencia para elas os amuletos é um velho agonizante que, naquele momento, parece tomado de inspiração divina. ${ }^{16}$

A segunda etapa - relatada no capítulo 9 ("As lágrimas de amor") - traz a lenda do amor de Ahy e Aoitin, contada pela avó de Carolina. Nela os dois indígenas vivem a dor da separação para, ao final, encontrarem o amor e permanecerem juntos inclusive após a morte, transformando-se em uma fonte. A narração é seguida, no capítulo 10 ("Balada no rochedo"), de uma balada em que a tamoia Ahy expressa sua mágoa, e que Carolina costuma cantar, graças

14. MARTINS, História da inteligência brasileira, p. 301-302.

15. MACEDO. A Moreninha, p. 116.

16. MACEDO. A Moreninha, p. 113-114. 
a uma antiga tradução feita por um frade português. A história de Ahy e Aoitin atribui ao romance de Macedo um caráter arcaico. A imagem da donzela solitária sobre o rochedo, entoando uma canção de dor e saudade, reporta-nos à figura da Iara indígena, mas também às ondinas dos pagãos europeus e à Loreley.

O amor de Augusto e Carolina é inserido, assim, em uma dupla moldura mítica (cristã e pagã) e em um caminho no qual se entrecruzam fontes europeias e indígenas. Para Wilson Martins, ${ }^{18}$ a despeito da frivolidade e sentimentalismo de $A$ Moreninha, não devemos deixar de reconhecer a alusão simbólica, o empenho nacionalista, o valor do perene e do sagrado que o romance possui. Mesmo Tania Rebelo Costa Serra - bastante crítica em relação à Moreninha e que prefere as obras de fase posterior - reconhece que o livro não é "inteiramente desprovido de valor narrativo" e que "permane[ce] atual". ${ }^{19}$

É preciso, é claro, reconhecer que o projeto de $A$ Moreninha bem poderia ter sido realizado com mais elegância e requinte. Entre outros, seu humor poderia não ter o acento vulgar tão criticado por Antonio Candido. ${ }^{20} \mathrm{E}$ aquela dimensão mítico-simbólica apontada acima certamente é um diferencial positivo, mas representa antes uma exceção do que a regra, não sendo de fato a esfera em que Macedo se exercite com mais frequência.

Sua inclinação maior foi para a representação de cunho "realista" - um pendor que, para Macedo, é decorrente da própria natureza do romance. Em Os dois amores, ele coloca na boca de um dos personagens a afirmação:

- [...] pensas que os romances são mentiras?... [...] os romances têm sempre uma verdade por base; o maior trabalho dos romancistas consiste em desfigurar essa verdade de tal modo que os contemporâneos não cheguem a dar os verdadeiros nomes de batismo às personagens que aí figuram. ${ }^{21}$

17. Veja-se: Loreley (1801), de Clemens Brentano; e Não sei o que significa... [Ich weiss nicht, was soll es bedeuten...] (1824), de Heinrich Heine.

18. MARTINS, História da inteligência brasileira, p. 302.

19. SERRA. Joaquim Manuel de Macedo ou Os dois Macedos, p. 43-44.

20. CANDIDO. Macedo, realista e romântico, p. 17.

21. MACEDO. Os dois amores, p. 242. 
À guisa de comparação, vale mencionar que no mesmo texto, somente algumas páginas adiante, ${ }^{22}$ há uma descrição do poeta:

É belo vê-lo assim; parece que transportado contempla uma visão. Ninguém the fala, e êle sorri... se entristece... se espanta e murmura frases ininteligíveis como se estivesse conversando com algum ser invizível.

Será um louco? não: êle é um poeta [...]

Os poetas são homens que mal vivem neste nosso mundo, e que são senhores de mil mundos; habitam um espaço entre o céu e a terra, e falam a língua das aves e das flores, das montanhas e dos mares, dos fantasmas e dos anjos.

Os poetas são homens que sabem amar; os que não são poetas amam como todos, amam com êsse amor comum que se vê todos os dias, que não tem nada de novo, que tem bem pouco de belo.

O amor dos poetas é de um fogo que não se acende na terra, é um fogo como o do sol.

Os poetas são irmãos do sol; êles são os astros que iluminam o mundo como o sol ilumina o espaço. ${ }^{23}$

Enquanto o romancista observa e registra as minúcias do dia-a-dia, procurando em seguida dar-lhe ares ficcionais, o poeta é da mesma ordem dos astros e corporifica o estereótipo dito romântico: pálido, louco e incompreensível aos homens comuns. E seu amor não é o dos mexericos e ciúmes ordinários; é avassalador e eterno, tal como o de Ahy e Aoitin, em que se espelha o de Augusto e Carolina.

O padrão de romance de Macedo foi em especial sublevado em A luneta mágica (1869), texto carregado de ironia e crítica contra o Rio de JaneiroImpério. Advogados, funcionários públicos, comerciantes, senhoras de família, etc. são igualmente colocados sob a lupa da sátira inclemente. No entanto, ao contrário do que vemos não apenas em Macedo, mas no Romantismo brasileiro em geral, trata-se de uma narrativa que se embrenha pelo mágico e sobrenatural.

Macedo retoma a teoria de Paracelso que em 1591 descreveu os seres que habitam os quatro elementos: as sílfides ou elfos que moram no ar,

22. O trecho a seguir está na "História do meu amor", entregue pelo velho Rodrigues a Cândido e que este lê (MACEDO, Os dois amores, p. 256-257).

23. MACEDO. Os dois amores, p. 263. 
as ondinas ou ninfas na água, os pigmeus ou gnomos na terra, e as salamandras no fogo. Além disso, as sucessivas compras da luneta do mal, da luneta do bem e da luneta do bom-senso equivalem a um pacto demoníaco, pois a criatura mágica fornece ao personagem Simplício meio de vencer sua miopia física e até de enxergar o íntimo das pessoas e coisas, mas ela cobra um alto preço - o qual inclusive levará o protagonista a tentar o suicídio. A visão amplificada, ou seja, o conhecimento sem limites significa para Simplício a expulsão de seu paraíso inicial (ainda que ele não o reconhecesse inicialmente como tal).

A luneta mágica tem em seu âmago a contraposição de Bem e Mal, de ciência (Reis) e magia (Armênio), de superfície (aparência) e interior. A ideia central, porém, nada tem de maniqueísta, pois todos os Homens são, em alguma medida, bons e maus. Não há uma perspectiva única, e sim formas diferentes de olhar para as coisas. Nessa ênfase no "modo de olhar" para o mundo, Macedo segue o romântico alemão E. T. A. Hoffmann em seu conto O Mestre Pulga [Meister Floh] (1822), em que há uma luneta capaz de ler os pensamentos das pessoas. ${ }^{24}$ Por outro lado, também o tema do talismã, tal como desenvolvido em A pele de onagro [La Peau de chagrin], de Balzac (1831), deve ter contribuído para o texto de Macedo.

Enfim, o diapasão de Macedo não é de uma nota só, conforme notou Tania Rebelo Costa Serra, que sugere uma subdivisão de sua obra em duas fases: o Macedo das mocinhas, de 1844 a 1866; e o Macedo dos adultos, de 1867 a 1882. Cada uma dessas fases, por sua vez, estaria dividida em dois blocos: o alegre ou cômico, e o triste ou trágico. ${ }^{25}$

De modo geral, as obras para mocinhas narram histórias de namoros que terminam em casamento; as obras para adultos têm como substrato a sátira social e política. Entre os textos alegres estão A Moreninha (1844) e A luneta mágica (1869), entre os tristes: A nebulosa (1857) e As vítimas-algozes (1869).

Conforme contabilizou Antonio Candido, "em trinta e quatro anos de produtividade, [Macedo escreveu] vinte romances, doze peças de teatro, um poema [e] mais de dez volumes de variedades". ${ }^{26}$ Essa vasta produção foi relegada

24. Ver SÜSSEKIND. O sobrinho pelo tio, p. 31.

25. SERRA. Joaquim Manuel de Macedo ou Os dois Macedos, p. 241. Ver também SERRA. Antologia do romance-folhetim (1839 a 1870), p. 149.

26. CANDIDO, Antonio. Macedo, realista e romântico, p. 11. 
por muito tempo ao esquecimento pela crítica universitária. É bem verdade que A Moreninha nunca foi esquecida, chegando inclusive ao teatro, cinema e até quadrinhos. ${ }^{27}$ Também é verdade que nas últimas décadas outras obras, além do romance de estreia, vêm sendo reeditadas. Fundamental, porém, para a releitura e revalorização do legado de Macedo foi o exaustivo trabalho de Tania Rebelo Costa Serra, Joaquim Manuel de Macedo ou Os dois Macedos: A luneta mágica do II Reinado (1994). Desde então a academia tem desenvolvido cada vez mais trabalhos, principalmente no que se refere às obras satíricas, como $A$ carteira do meu tio (1855), Memórias do sobrinho do meu tio (1867-1868) e mesmo $A$ luneta mágica (1869). Teses e dissertações recentes - como de Valéria Augusti (UNICAMP, 1998), Angela Maria Gonçalves da Costa (UNICAMP, 2006), Leandro Thomaz de Almeida (UNICAMP, 2008) e Juliana Maia de Queiroz (UNICAMP, 2011), todas sob orientação da Prof ${ }^{a}{ }^{a}$ Dr $^{\mathrm{a}}$ Márcia Abreu - merecem destaque nesse sentido.

Quanto à releitura da poesia de Macedo, a já mencionada tese de Angela Maria Gonçalves da Costa comprova que esse estudo também já teve início.

Penso que esse trabalho de recuperação é fundamental. Faço minha a posição de Tania Rebelo Costa Serra, ${ }^{28}$ que afirmou que não podemos nos dar ao luxo de jogar ao ostracismo um autor como Macedo que - a despeito de lacunas e fragilidades - também possui méritos em quantidade suficiente para ter um lugar assegurado em nossa pesquisa universitária.

Fora isso, trata-se de autor indelével da nossa literatura, uma vez que contribuiu com sólida camada de tijolos à formação de gerações de leitores e escritores. Basta lembrarmos, a título de ilustração, das palavras de Graciliano Ramos em Infância:

Nesse tempo eu andava nos fuzuês de Rocambole. Jerônimo Barreto me fazia percorrer diversos caminhos: revelara-me Joaquim Manuel de Macedo, Júlio Verne, afinal Ponson de Terrail, em folhetos devorados na escola, debaixo das laranjeiras do quintal, nas pedras do Paraíba, em cima do caixão de velas, junto ao dicionário que tinha bandeiras e figuras. ${ }^{29}$

27. QUEIROZ. Em torno da sátira política e da crítica social nos romances de Macedo, online.

28. Conforme lemos, p. ex., em Joaquim Manuel de Macedo ou Os dois Macedos, p. 235.

29. RAMOS. Infância, p. 232. 
Ficção lida com tanto entusiasmo deve ter fertilizado o espírito e as letras não apenas de Graciliano Ramos, mas eventualmente de muitos nomes de destaque de nossa cultura - e é aí que reside a força mais concreta de um escritor. A nova geração de pesquisadores mostra o quanto Macedo ainda é vivo e atuante.

\section{Macedo and the romantic novel}

Abstract: Joaquim Manuel de Macedo was a highly acclaimed writer among nineteenth - century readers, although posterity treated his work with many reservations. Despite the severity of his critics, Macedo's contribution undeniably cannot be limited to his books, but extends to the very concept of the novel as a genre during Brazilian Romanticism. This novelistic concept is fueled by the observation of everyday life as well as by aesthetic ideas brought to light by European Romanticism. Differently, however, in A luneta mágica [The Magic Looking Glass] Macedo employed aspects of the fantastic to produce a daringly critical and creative novel that contrasts vividly with other Romantic works in Brazil. Keywords: Joaquim Manuel de Macedo; A luneta mágica; A Moreninha.

$$
\text { Referências }
$$

\footnotetext{
ALENCAR, Heron de. José de Alencar e a ficção romântica. In: COUTINHO, Afrânio (Dir.). A literatura no Brasil. 3. ed. rev. e aum. Rio de Janeiro: J. Olympio; Niterói: EDUFF, 1986, v. 3, p. 231-321.

BEDÊ, Ana Luiza Reis. Joaquim Manuel de Macedo como folhetinista panfletário: uma leitura de $A$ carteira de meu tio. Anais do XI Congresso Internacional da ABRALIC "Tessituras, interações, convergências", realizado na USP/São Paulo, de 14.07 a 17.07.08. Consulta em 10.03.11. Disponível em http://www.abralic.org.br/anais/ cong2008/ AnaisOnline/simposios/pdf/075/ANA_BEDE.pdf .

CANDIDO, Antonio. Macedo, realista e romântico. In: MACEDO, Joaquim Manoel de. A Moreninha. São Paulo: Livraria Martins Ed., 1952, p. 9-23.

CANDIDO, Antonio. Formação da literatura brasileira; Momentos decisivos. 6. ed. Belo Horizonte: Itatiaia, 1981. v. 2 (1836-1880).

COSTA, Angela Maria Gonçalves da. Uma trajetória do esquecimento: o poema A Nebulosa de Joaquim Manuel de Macedo, e sua recepção crítica. 2006. Tese (Doutorado em Teoria e História Literária). IEL, Universidade Estadual de Campinas.
} 
LEMOS, Maria José Cardoso. Memórias de um narrador distanciado: diálogos entre Machado e Macedo. Consulta em 10.03.11. Disponível em http://www.filologia.org. br/ machado_de_assis/Mem\%C3\%B3rias\%20de\%20um\%20narrador\%20distanciado\%20 di $\%$ C3\%A1logos\%20entre\%20Machado\%20e\%20Macedo.pdf .

LINHARES, Temístocles. História crítica do romance brasileiro (1728-1981). Belo Horizonte: Itatiaia; São Paulo: Edusp, 1987. (Coleção Reconquista do Brasil, 116). v. 1.

MACEDO, Joaquim Manoel de. A Moreninha. São Paulo: Livraria Martins Ed., 1952.

MACEDO, Joaquim Manoel de. Os dois amores. São Paulo: W. M. Jackson, s.d. (Grandes Romances Universais, 12).

MARTINS, Wilson. História da inteligência brasileira. 2. ed. São Paulo: Cultrix, 1978. v. 2 (1794-1855).

MEYER, Marlyse. Folhetim: Uma história. São Paulo: Companhia das Letras, 1996.

MOISÉS, Massaud. História da literatura brasileira. São Paulo: Cultrix, 1984. v. 2: "O romantismo".

NEJAR, Carlos. História da literatura brasileira: Da Carta de Caminha aos nossos dias. São Paulo: Leya, 2011.

PROENÇA FILHO, Domício. O filho do pescador: o primeiro romance brasileiro. In: TEIXEIRA E SOUSA, Antônio. O filho do pescador. Rio de Janeiro: Artium, 1997, p. VII-XXXIX.

QUEIROZ, Juliana Maia de. Em torno da sátira política e da crítica social nos romances de Macedo. Consulta em 10.03.11. Disponível em http://www.caminhosdoromance.iel. unicamp.br/estudos/abralic/em_torno_satira.doc .

RAMOS, Graciliano. Infância. São Paulo: Livraria Martins, 1961.

SERRA, Tania Rebelo Costa. Joaquim Manuel de Macedo ou Os dois Macedos: A luneta mágica do II Reinado. Rio de Janeiro: Fundação Biblioteca Nacional; Departamento Nacional do Livro, 1994. (Coleção Celso Cunha, 4).

SERRA, Tania Rebelo Costa. Antologia do romance-folhetim (1839 a 1870). Brasília: Editora UnB, 1997.

SÜSSEKIND, Flora O sobrinho pelo tio. Literatura e sociedade. São Paulo (USP), v. 1, p. 30-43, 1996. 